\title{
Article
}

\section{The Influence of Transitional Metal Dopants on Reducing Chlorine Evolution during the Electrolysis of Raw Seawater}

\author{
Prajwal Adiga ${ }^{1}\left(\right.$, Nathan Doi ${ }^{2}$, Cindy Wong ${ }^{1}$, Daniel M. Santosa ${ }^{2}$, Li-Jung Kuo ${ }^{2}$, Gary A. Gill ${ }^{2}{ }^{\mathbb{D}}$, \\ Joshua A. Silverstein ${ }^{2}$, Nancy M. Avalos ${ }^{2}$, Jarrod V. Crum ${ }^{2}$, Mark H. Engelhard ${ }^{2}$, Kelsey A. Stoerzinger 1,3,* \\ and Robert Matthew Asmussen 2,*(D) \\ 1 School of Chemical, Biological and Environmental Engineering, Oregon State University, \\ Corvallis, OR 97331, USA; adigap@oregonstate.edu (P.A.); wongc@oregonstate.edu (C.W.) \\ 2 Energy and Environment Directorate, Pacific Northwest National Laboratory, Richland, WA 99352, USA; \\ nathan.doi@sjsu.edu (N.D.); daniel.santosa@pnnl.gov (D.M.S.); lijkuo@pnnl.gov (L.-J.K.); \\ garyagill@gmail.com (G.A.G.); joshua.silverstein@pnnl.gov (J.A.S.); nancy.avalos@pnnl.gov (N.M.A.); \\ jarrod.crum@pnnl.gov (J.V.C.); mark.engelhard@pnnl.gov (M.H.E.) \\ 3 Physical and Computational Sciences Division, Pacific Northwest National Laboratory, \\ Richland, WA 99352, USA \\ * Correspondence: kelsey.stoerzinger@oregonstate.edu (K.A.S.); matthew.asmussen@pnnl.gov (R.M.A.)
}

check for updates

Citation: Adiga, P.; Doi, N.; Wong, C.; Santosa, D.M.; Kuo, L.-J.; Gill,

G.A.; Silverstein, J.A.; Avalos, N.M.; Crum, J.V.; Engelhard, M.H.; et al.

The Influence of Transitional Metal Dopants on Reducing Chlorine Evolution during the Electrolysis of Raw Seawater. Appl. Sci. 2021, 11 , 11911. https://doi.org/10.3390/ app112411911

Academic Editor: Dongkyu Lee

Received: 31 July 2021

Accepted: 19 November 2021

Published: 15 December 2021

Publisher's Note: MDPI stays neutral with regard to jurisdictional claims in published maps and institutional affiliations.

Copyright: (c) 2021 by the authors. Licensee MDPI, Basel, Switzerland. This article is an open access article distributed under the terms and conditions of the Creative Commons Attribution (CC BY) license (https:/ / creativecommons.org/licenses/by/ $4.0 /)$.
Featured Application: This work is focused on developing electrocatalysts that can be used to realize direct seawater electrolysis as a means of energy storage or hydrogen production.

Abstract: Electrocatalytic water splitting is a possible route to the expanded generation of green hydrogen; however, a long-term challenge is the requirement of fresh water as an electrolyzer feed. The use of seawater as a direct feed for electrolytic hydrogen production would alleviate fresh water needs and potentially open an avenue for locally generated hydrogen from marine hydrokinetic or off-shore power sources. One environmental limitation to seawater electrolysis is the generation of chlorine as a competitive anodic reaction. This work evaluates transition metal (W, Co, Fe, Sn, and $\mathrm{Ru}$ ) doping of Mn-Mo-based catalysts as a strategy to suppress chlorine evolution while sustaining catalytic efficiency. Electrochemical evaluations in neutral chloride solution and raw seawater showed the promise of a novel Mn-Mo-Ru electrode system for oxygen evolution efficiency and enhanced catalytic activity. Subsequent stability testing in a flowing raw seawater flume highlighted the need for improved catalyst stability for long-term applications of Mn-Mo-Ru catalysts. This work highlights that elements known to be selective toward chlorine evolution in simple oxide form (e.g., $\mathrm{RuO}_{2}$ ) may display different trends in selectivity when used as isolated dopants, where $\mathrm{Ru}$ suppressed chlorine evolution in Mn-based catalysts.

Keywords: electrolysis; chlorine evolution; oxygen evolution; seawater

\section{Introduction}

The electrocatalytic splitting of water to produce hydrogen can be used to store renewable electricity as either a chemical fuel or as a feedstock. However, this process currently requires an ultra-pure water feed [1], which would thus strain drinking water supplies at hydrogen production levels required for a fleet of fuel cell vehicles [2]. Seawater presents an abundant water resource, but it is yet to be utilized for hydrogen production due to the complexity it presents as an electrolyte and energy-intensive purification processes. If the associated challenges were overcome, seawater electrolysis could generate $\mathrm{H}_{2}$ fuel from green electricity at coastal sites, on board marine vessels or platforms, or submersed at marine hydrokinetic platforms [3]. 
A primary limiter of energy efficiency is the sluggishness of the reaction that counters the hydrogen evolution reaction (HER): the oxygen evolution reaction (OER), which in seawater also competes with the hazardous chlorine evolution reaction (CER):

$$
\begin{gathered}
\text { OER, alkaline: } 4[\mathrm{OH}]^{-} \rightarrow 2 \mathrm{H}_{2} \mathrm{O}+\mathrm{O}_{2}+4 \mathrm{e}^{-} \\
\text {OER, acidic: } 2 \mathrm{H}_{2} \mathrm{O} \rightarrow 4 \mathrm{H}^{+}+\mathrm{O}_{2}+4 \mathrm{e}^{-} \\
\text {E_OER }^{0}=+1.23 \mathrm{~V}-0.059 \mathrm{pH} \\
\text { CER, acidic: }[2 \mathrm{Cl}]^{-} \rightarrow[\mathrm{Cl}]_{2}+[2 \mathrm{e}]^{-} \\
\text {E_CER }{ }^{0}=+1.358 \mathrm{~V} \mathrm{SHE}, \mathrm{pH} 0
\end{gathered}
$$

The kinetics of the OER are generally slower relative to CER due to the requirement for the transfer of four electrons and protons per oxygen molecule, while the CER is a two-electron process. At $\mathrm{pH}>3$, chloride can be oxidized to form hypochlorous acid $(\mathrm{HOCl}$, $\mathrm{pH} 3-7)$, and at $\mathrm{pH}>7$, hypochlorite is formed $\left(\mathrm{OCl}^{-}\right)$[4]. Most research on maximizing oxygen evolution activity to date has focused on highly acidic [5-8] or alkaline [9-12] media, and information regarding the selectivity toward chlorine evolution often stems from the chlor-alkali industry in acidic environments where CER is preferred [13]. Although precious metal oxides (e.g., $\mathrm{IrO}_{2}$ ) are highly active for OER in acidic media, such materials are similarly highly active for CER in chloride-containing media $[14,15]$.

In the neutral conditions of seawater [16-18], electrolysis studies are scarce and, instead, often incorporate additional buffering [19]. Historically, research in such media has focused on metal oxides primarily composed of Mn [20-22], Ni [16,23], and Co [19,20,24], often with additional elements, such as Fe or W. Considering abundance and a promising price point [24], we focus here on Mn-based oxides, which are stable and have demonstrated good Faradaic efficiency in a wide range of electrolyte $\mathrm{pH}$. MnOx electrocatalysts (often supported on an $\mathrm{IrO}_{2} /$ Ti substrate [25]) have demonstrated good selectivity ( $>90 \%$ ) toward OER in chlorine-containing electrolyte, with the remainder of the current going toward CER and oxidative dissolution in the form of $\mathrm{MnO}_{4}{ }^{-}$[21]. However, these electrodes suffered from mechanical instability during cycling at appreciable current densities. The incorporation of $\mathrm{Mo}^{6+}$ improved durability and Faradaic efficiency [26]. The further incorporation of $\mathrm{W}^{6+}$ maintained this performance while improving OER activity (lowering overpotential), which has been attributed in part to its enhancement of oxide conductivity [23]. However, numerous other potential metals may serve a similar role, perhaps with better efficacy and stability.

In the present work, we consider the OER activity of a Mn-Mo-based oxide electrocatalyst in chlorine-containing neutral electrolytes and raw seawater, comparing the performance upon the gradual incorporation of $\mathrm{W}, \mathrm{Fe}, \mathrm{Co}, \mathrm{Sn}$, and $\mathrm{Ru}$ as dopants. It is well documented that the doping of transition and noble metals into electrocatalysts [27] and photocatalysts $[28,29]$ can enhance their water splitting capacity, and a similar approach was pursued within. We showcase the optimum dopant levels for each element and highlight the strong performance of a Mn-Mo-Ru catalyst in both suppressing the CER and showing enhanced catalytic activity for OER. The stability of the Mn-Mo-Ru catalyst was also investigated in extended testing in a continuous raw seawater feed, a comparable scenario for a membrane-less, direct seawater-fed electrolyzer. The findings of this work highlight that the issues withholding the realization of direct seawater electrolysis can be overcome and open a potentially vast resource for green hydrogen to meet many emerging global needs.

\section{Materials and Methods}

The OER catalyst electrodes were fabricated via electrodeposition. The plate electrodes were fabricated using Ti sheet, $2 \mathrm{~mm}$ thickness, spot welded to a 304 stainless steel rod. The plates were first etched in concentrated (18.4 mol/L) $\mathrm{H}_{2} \mathrm{SO}_{4}$ at $80-85^{\circ} \mathrm{C}$ for $30 \mathrm{~min}$ [30]. The plates were then rinsed in deionized water (DDI, $18.2 \mathrm{M} \Omega \cdot \mathrm{cm}$ ) and dried in a hot 
air stream. Following drying, an $\mathrm{IrO}_{2}$ base layer was placed onto the plate via thermal decomposition. A solution of iridium (III) chloride (Aldrich) in butanol was manually deposited onto the etched surface and placed into a $450{ }^{\circ} \mathrm{C}$ oven for $10 \mathrm{~min}$ and weighed. This process was repeated three additional times until $\sim 2 \mathrm{mg}$ of $\mathrm{IrO}_{2}$ was deposited.

The electrodeposition stock solutions were prepared in DDI, $18.2 \mathrm{M} \Omega \cdot \mathrm{cm}$, and then acidified to $\mathrm{pH}$ 1-3 (dependent on test) with concentrated $\mathrm{H}_{2} \mathrm{SO}_{4}$. The metal salts were then added in sequence of the dopant, the sodium molybdate dihydrate (Sigma-Aldrich, St. Louis, MO, USA) and then the manganese sulfate monohydrate (Sigma-Aldrich, St. Louis, MO, USA) in the target molar ratios. The dopant salts used were iron (II) sulfate heptahydrate (Sigma-Aldrich, St. Louis, MO, USA), cobalt (II) sulfate heptahydrate (Sigma-Aldrich, St. Louis, MO, USA), ruthenium (III) chloride (Sigma-Aldrich, St. Louis, MO, USA), tin (IV) chloride pentahydrate (Sigma-Aldrich, St. Louis, MO, USA), and sodium tungstate dihydrate (Sigma-Aldrich, St. Louis, MO, USA). A $60 \mathrm{~mL}$ aliquot of the stock solution was then placed in a glass beaker and heated to $80{ }^{\circ} \mathrm{C}$. The $\mathrm{IrO}_{2}$-coated electrode and a $\mathrm{Pt}$ counter electrode were placed into the beaker, and a DC power source attached with $0.06 \mathrm{~A}$ at $5.0 \mathrm{~V}$ passed for $20 \mathrm{~min}$. Following the deposition, the electrode was removed, rinsed with DDI, dried, weighed, and returned to a fresh stock solution. The deposition was then repeated twice with weight measured in between. The electrodes were named based on their starting concentration of the deposition solution. A ratio of $0.2 \mathrm{M} \mathrm{M}-0.003 \mathrm{M}$ Mo was used for all catalysts based on the literature and preliminary testing. The dopant concentrations (for $\mathrm{W}, \mathrm{Ru}, \mathrm{Fe}, \mathrm{Sn}$, and $\mathrm{Co}$ ) were used to define the sample name of the electrodes, while the Mn-Mo values were not included, e.g., Mn-Mo-0.XXX M Y where $\mathrm{XXX}$ is the dopant concentration and $\mathrm{Y}$ is the dopant element. The composition of the electrodes was measured using quantitative energy-dispersive X-ray spectroscopy (EDS) using the average mapped signal from a $250 \times 250 \mu \mathrm{m}$ region on the sample surface. The measurements were performed on a JSM-7001F microscope (JEOL USA, Inc., Peabody, MA, USA) with an XFlash 6 I 60 EDS Si-drift detector (SDD; Bruker, Kennewick, WA, USA).

Electrochemical measurements, both linear sweep voltammetry, chronoamperometry and chronopotentiometry, were made using a Solartron ${ }^{\circledR} 1287$ (Ametek, Berwyn, PA, USA), Biologic VSP-300 potentiostat (BioLogic, Sayisset-Pariset, France), or a CH Instruments $600 \mathrm{E}$ (CH Instruments, Austin, TX, USA) using a Ag/ AgCl reference electrode $(0.230 \mathrm{~V}$ vs. the standard hydrogen electrode, SHE) and a Pt wire counter electrode. Laboratory measurements were made using an H-cell configuration with a Nafion ${ }^{\circledR} 117$ membrane separating the compartments, unless otherwise noted. Solution samples were collected using a pipette during and at the end of the experimental run. Between tests, the cell was emptied, acid washed, and rinsed thoroughly in $18.2 \mathrm{M} \Omega \cdot \mathrm{cm}$ water, and a new solution was added before the test electrode was returned to the solution. Electrolytes considered were DDI containing $\mathrm{NaCl}(0.5 \mathrm{~mol} / \mathrm{L}), \mathrm{MgCl}_{2}(0.5 \mathrm{~mol} / \mathrm{L}), 0.1 \mathrm{M}$ phosphate-buffered $0.5 \mathrm{M}$ $\mathrm{NaCl}$ (all from Sigma-Aldrich, St. Louis, MO, United States), artificial seawater (ASW) [31], or raw seawater (taken from Sequim Bay in Washington State, filtered at $0.45 \mu \mathrm{m}$, and stored in a fridge at $5{ }^{\circ} \mathrm{C}$ ).

The measure of $\mathrm{Cl}_{2}$ generation was determined using iodometric titration on the collected samples as has been used previously [26]. The $\mathrm{Cl}_{2}$ generated will convert to $\mathrm{HOCl}$ in the vessel. Iodide (as sodium iodide, (Sigma-Aldrich, St. Louis, MO, USA) was added to the sample to react with the $\mathrm{HOCl}$. A titration with sodium thiosulfate (Sigma-Aldrich, St. Louis, MO, USA) was then performed to determine the amount of iodide that had reacted and, in turn, determine the $\mathrm{HOCl}$ concentration. The faradaic efficiency for $\mathrm{O}_{2}$ was then calculated as the difference between the charge passed and the charge required for the hypochlorite generated.

The surface of the Mn-Mo-Ru electrodes was analyzed using a Bruker D8 Advance (Bruker, Madison, WI, USA) diffraction system configured with a Cu-target, Bragg-Brentano focusing optics with fix slits $\left(0.3^{\circ}\right)$, goniometer radius of $250 \mathrm{~mm}$, and a Lynxeye 1-D detector $\left(3^{\circ}\right.$ window). Samples were scanned from $5-90^{\circ} 2 \theta$, with a step size of $0.015^{\circ} 2 \theta$ and hold time $1.5 \mathrm{~s} / \mathrm{step}$. The samples were rotated during data collection to minimize 
preferred orientation effects. The patterns were analyzed using EVA (version 4.1) software to remove $\mathrm{K} \alpha 2$ peaks and the background. Then, search/match feature was used to identify crystalline phases in the patterns using the chemistry filter and the International Crystal Diffraction Data (PDF2, version 2019).

The Mn-Mo-Ru electrodes were analyzed using X-ray photoelectron spectroscopy (XPS) utilizing a Thermo Fisher Nexsa spectrometer (ThermoFisher, Waltham, MA, United States). This system uses a focused monochromatic Al K $\alpha$ X-ray (1486.7 eV) source for excitation and a spherical section analyzer. The high energy resolution spectra were collected using a pass energy of $50 \mathrm{eV}$ with a step size of $0.1 \mathrm{eV}$. For the $\mathrm{Ag} 3 \mathrm{~d}_{5 / 2}$ line, these conditions produced a FWHM of $0.82 \mathrm{eV} \pm 0.05 \mathrm{eV}$. The spectra were collected with an electron emission angle of $60^{\circ}$ relative to surface normal.

\section{Results}

\subsection{Electrode Fabrication and Structure}

The electrodeposition process produced electrodes with a cracked mud structure, with the Mn-Mo-X catalyst deposited on top of a sub-layer of thermal decomposition-produced IrO2. The $\mathrm{IrO}_{2}$ layer prevents insulation of the titanium substrate by oxidation [25]. The thermal decomposition process deposited $\sim 0.0020 \mathrm{~g} / \mathrm{cm}^{2}$ of $\mathrm{IrO}_{2}$. To ensure the complete coverage of, first, the $\mathrm{IrO}_{2}$ layer on the $\mathrm{Ti}$ and, then, the Mn-Mo catalyst, important for analysis of Faradaic efficiency toward OER, deposition conditions were tailored to achieve complete attenuation by EDS (information depth on the order of $\sim$ microns). Three sequential electrodeposition cycles of $20 \mathrm{~min}$ each at $80^{\circ} \mathrm{C}$ were used to generate a homogenous catalyst layer. Figure 1 shows the resulting catalyst layer yielding complete coverage of the electrode surface by EDS, similar to prior work [22]. Electrodeposition at room temperature or with a continuous deposition at $80{ }^{\circ} \mathrm{C}$ generated incomplete and heterogeneous catalyst layers on the electrode surface. Beyond three cycles, flaking from over-deposition was observed. The deposition cycles resulted in $\sim 0.0500 \mathrm{~g} / \mathrm{cm}^{2}$ of catalyst deposited.
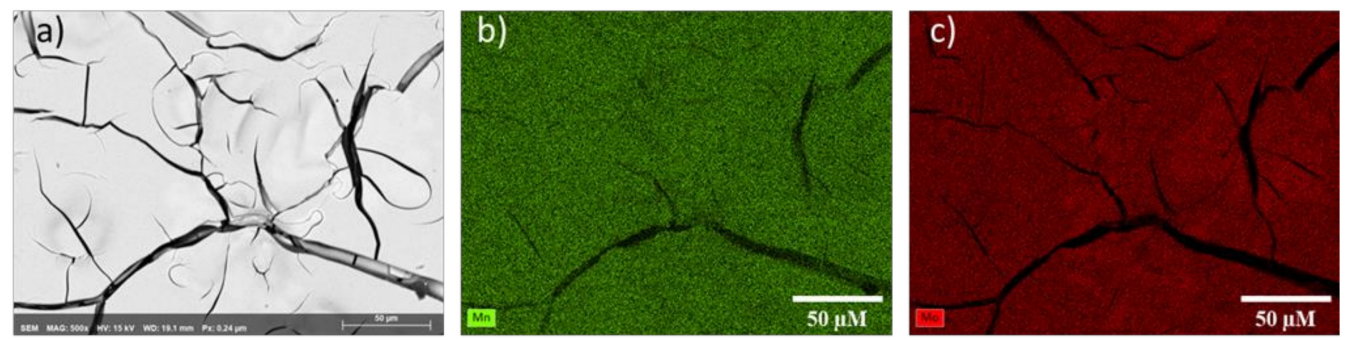

Figure 1. (a) SEM micrograph and the corresponding EDS maps for (b) Mn and (c) Mo for a 0.2 M Mn-0.003 M Mo catalyst with three $20 \mathrm{~min}$ electrodeposition cycles at $80^{\circ} \mathrm{C}$. There was no signal from the underlying Ti or Ir layers.

The inclusion of dopants at various levels in the Mn-Mo-X catalyst did not distort the overall cracked mud structure (see SEM images in Figure S1). Some heterogeneous distribution of the catalyst elements was observed as small "bumps" on the catalyst surface. EDS mapping highlighted the variations in element distribution through the catalysts. As an example, Figure 2a shows the SEM image of a Mn-Mo-0.006 M Ru electrode. While the composition appeared generally uniform across the film, there is also a Mn-rich region (Figure 2b) that is depleted in Mo (Figure 2c) and Ru (Figure 2d). The "cracks" in the microstructure gave a stronger Mn signal, suggesting the Mn distribution may vary with electrode thickness. While the distribution of the Ru in Figure $2 \mathrm{~d}$ appeared homogenous, magnification of the catalyst surface in Figure 2e showed "bumps" on the catalyst surface. EDS spot analysis showed that the flat region contained only Mn and Mo, whereas the bumps also contained $\mathrm{Ru}$ (Table 1 ). As a result of this heterogenous composition profile, the quantification of the dopant level and Mn/Mo/X ratios was limited with EDS. Thus, electrodes are referred to by the starting electrodeposition solution concentration, where increased solution concentration results in increased electrode dopant concentration. 

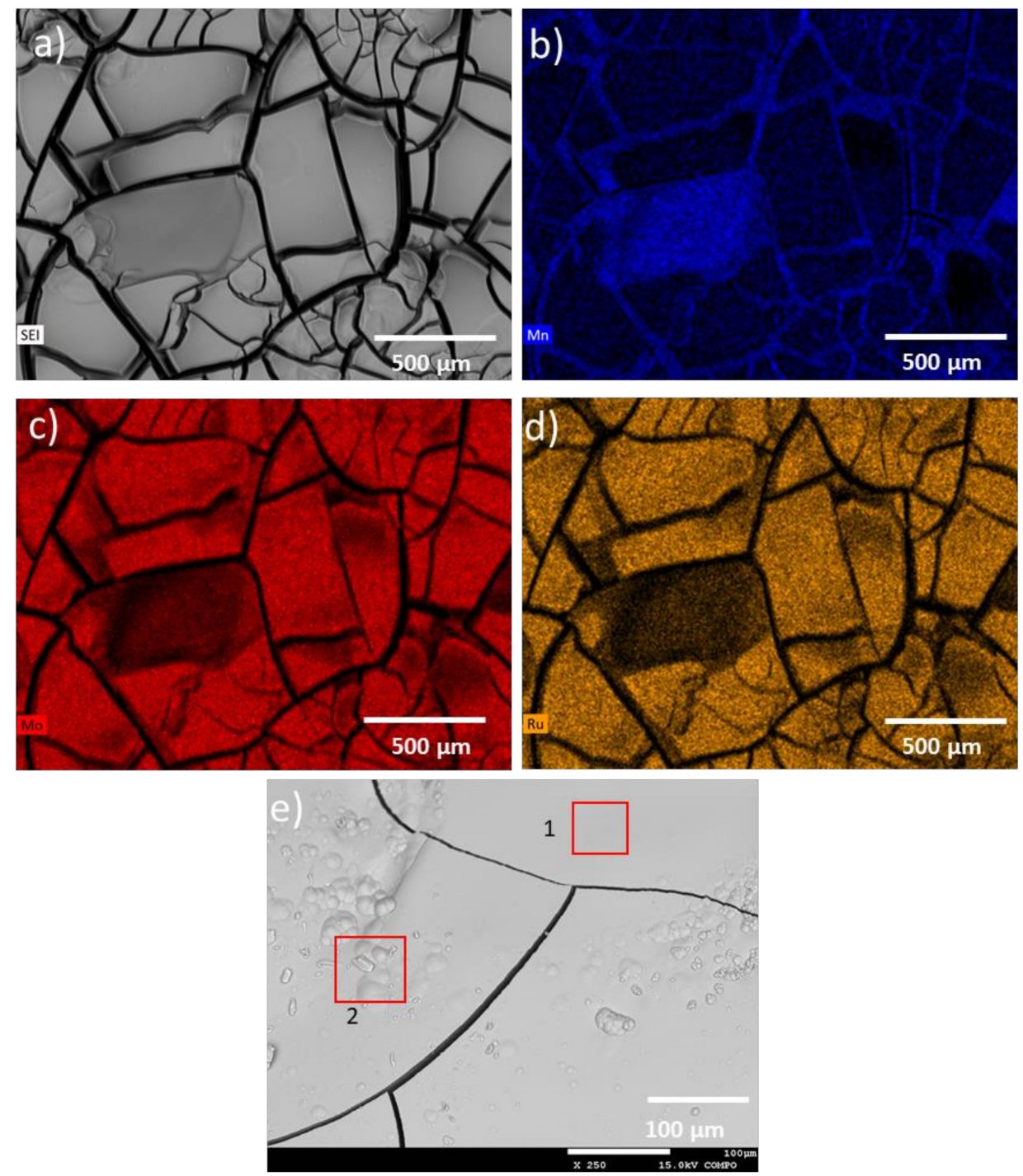

Figure 2. (a) SEM micrograph and corresponding EDS maps for (b) Mn, (c) Mo, and (d) Ru showing a Mn-rich region. (e) SEM micrograph at higher resolution on the Mn-Mo-0.006 M Ru electrode showing the heterogeneous bumps on the sample surface. The red boxes denote the regions quantified in Table 1.

Table 1. Composition of the regions analyzed by EDS in Figure 2e.

\begin{tabular}{ccccc}
\hline Spectrum & O (at\%) & Mn (at\%) & Mo (at\%) & Ru (at\%) \\
\hline 1 & 58.23 & 41.49 & 0.28 & 0.00 \\
2 & 58.17 & 41.29 & 0.40 & 0.15 \\
\hline
\end{tabular}

The XRD pattern of both the Mn-Mo-0.006 M Ru and Mn-Mo-0.009 M Ru electrodes showed the majority of the pattern arising from $\mathrm{MnO}_{2}$ with a strong signal from the underlying $\mathrm{IrO}_{2}$ layer (Figure 3). The low concentration of $\mathrm{Ru}$ and the overlap in the XRD features of its oxides make it challenging to assess potential phase segregation. 


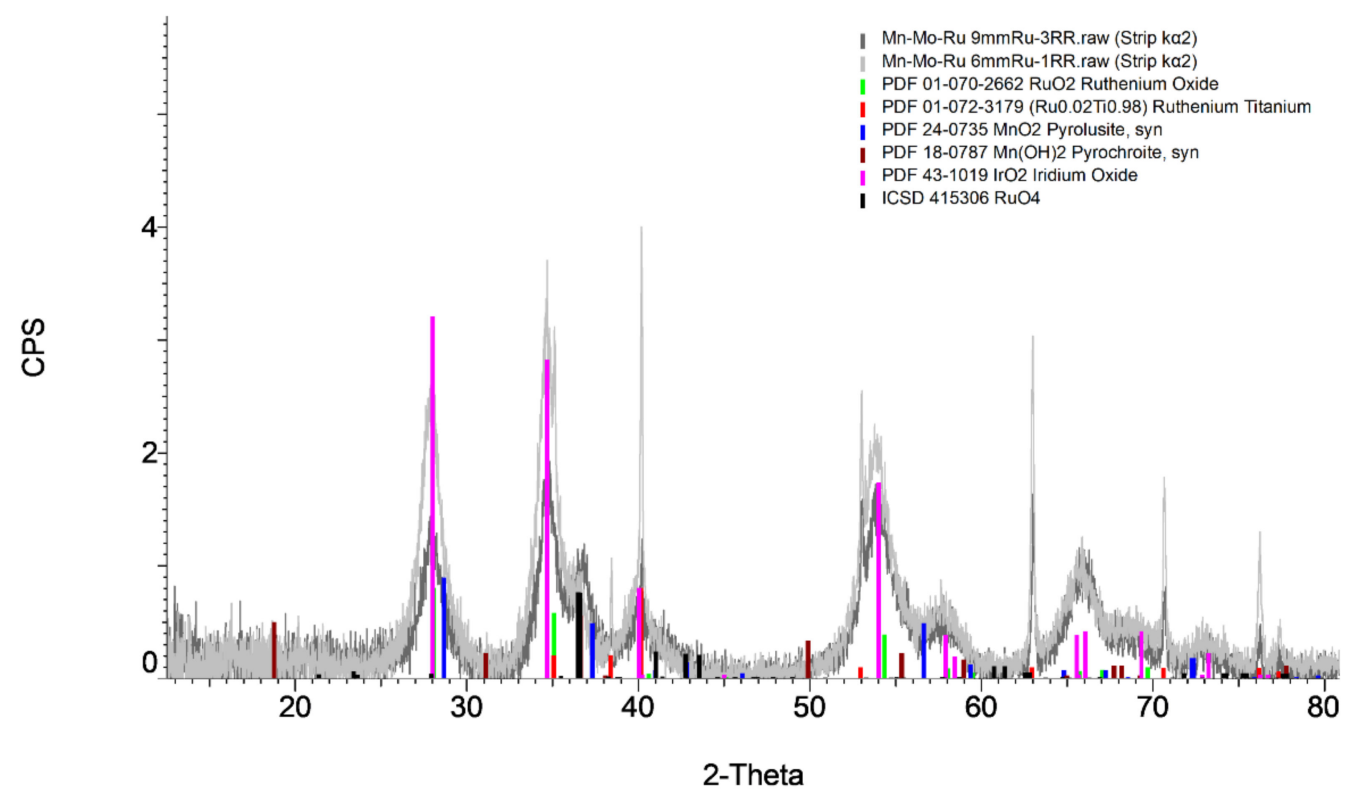

Figure 3. XRD patterns of the Mn-Mo-0.006 M Ru and Mn-Mo-0.009 M Ru electrodes and associated peak fits. $\mathrm{CPS}=$ counts per second.

To probe the oxidation state of the Mn-Mo-0.009 M Ru electrode, characterization with XPS was also performed, and the survey scan can be found in Figure S2a. Analysis of both the $\mathrm{Ru} 3 \mathrm{p}$ region and the $\mathrm{Ru} 3 \mathrm{~d}$ region showed the presence of $\mathrm{Ru}$ in the $\mathrm{Ru}$-containing electrode and the absence of $\mathrm{Ru}$ in the Mn-Mo electrode (Figure S2b-e). Peak fitting of the $R u 3 d_{5 / 2}$ peak showed the majority of the Ru present as $\mathrm{Ru}^{6+}$ (Figure $4 \mathrm{a}$ ). Other $\mathrm{Ru}$ oxidation states are possible but are challenging to resolve close to the C1s peak. The assessment accounted for the majority of $\mathrm{Ru} 3 \mathrm{~d}_{5 / 2}$ at $282.4 \mathrm{eV}$ as $\mathrm{Ru}^{6+}$ based on published reference binding energy for $\mathrm{RuO} 3$ [32]. $\mathrm{Ru}^{8+}$ can be difficult to detect because of peak overlap with the $\mathrm{C} 1 \mathrm{~s}$ line. In order to verify that we accounted for the majority of detected $\mathrm{Ru}$, we used the Thermo Fisher Nexsa spectrometer elemental sensitivity factors and $\mathrm{Ru}$ peak area ratios. The sensitivity factor (SF) for $R u 3 d_{5 / 2}$ and $R u 3 p_{3 / 2}$ was 8.74 and 8.78 , respectively, for a SF ratio of 0.996 . The calculated peak area after peak fitting the $\mathrm{Ru}$ $3 d_{5 / 2}$ was 29,323 counts, whereas the peak area for $R u 3 d_{3 / 2}$ was 29,671 counts for a $(R u$ $\left.3 \mathrm{~d}_{5 / 2}\right) /\left(\operatorname{Ru} 3 \mathrm{~d}_{3 / 2}\right)$ area ratio of 0.988 . Since the sensitivity factor and peak area ratios were so similar, the majority of the Ru measured was accounted for at $282.4 \mathrm{eV}$. Analysis of the Mo $3 \mathrm{~d}$ region showed $\mathrm{Mo}^{6+}$ (Figure $4 \mathrm{~b}$ ), and the $\mathrm{Mn} 3 \mathrm{~d}$ region showed primarily $\mathrm{Mn}^{4+}$ (Figure 4c). Further work is needed to quantify the ratio Ru species both before and after testing. Ru stability is dictated by its oxidation state in the catalyst and when oxidized $\left(\mathrm{Ru}^{8+}\right)$ will be far less stable leading to a decrease in catalytic activity [33]. A similar trend would be expected for other transition metal dopants. 

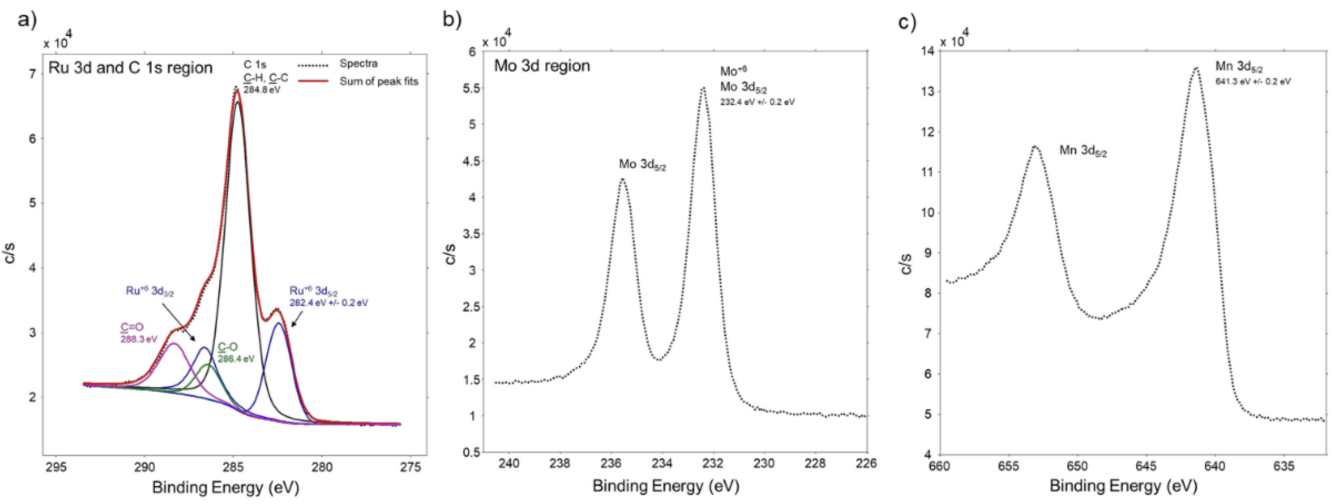

Figure 4. (a) XPS spectra and spectral fits for the (a) Ru 3d, (b) the Mn 3d, and (c) the Mo 3d regions from a Mn-Mo-Ru-0.009 M electrode. The survey scan can be found in the Supplementary Materials, Figure S2.

\subsection{OER Efficiency in Saline and Seawater Environments}

The performance of the electrodes was assessed on efficiency toward the OER over the CER, represented as the faradaic efficiency (FE) for OER, and the overall catalytic performance, represented as total charge passed at a given applied potential for $30 \mathrm{~min}$ (normalized by electrode geometric area). Electrodes that suppress the CER while facilitating the rate of OER are promising candidates for further development. In a $30 \mathrm{~min}$ exposure at $1.4 \mathrm{~V}$ vs. $\mathrm{Ag} / \mathrm{AgCl}$, an $\mathrm{IrO}_{\mathrm{x}}$ had a faradaic efficiency of only $18 \%$ toward OER $\left(14.7 \mathrm{C} / \mathrm{cm}^{2}\right)$, while a Mn-Mo electrode measured $91 \%$ faradaic efficiency $\left(31 \mathrm{C} / \mathrm{cm}^{2}\right)$.

The influence of various dopant levels on the Mn-Mo electrodes on OER faradaic efficiency in neutral chloride $(0.5 \mathrm{M} \mathrm{NaCl})$ environments is shown in Figure 5. In Figure 5a, the addition of Co to the Mn-Mo provided efficiencies $>95 \%$ relatively consistently for the tested compositions, with the exception being $0.009 \mathrm{M} \mathrm{Co}$. Increasing to Mn-Mo-0.1 M Co created a more physically stable electrode. For the inclusion of Fe (Figure 5b), the best performance was measured for electrodes Mn-Mo-0.01 M Fe, Mn-Mo-0.1 M Fe, and Mn-Mo-0.02 M Fe. Below 0.01 M Fe addition, stability and efficiency were compromised. A Mn-Mo-0.003 M W electrode was the best performing of the $\mathrm{W}$ set with consistent $>94 \%$ efficiency for OER (Figure 5d). We observed a drop in $\mathrm{pH}$ over time in the unbuffered neutral chloride electrolyte, possibly due to the inability of the Nafion ${ }^{\circledR}$ membrane to exchange the protons at the proton generation/consumption rate. The inclusion of these dopants (W, Fe, and $\mathrm{Co}$ ) also increased the OER faradaic efficiency and/or the charge passed toward OER in circum-neutral phosphate-buffered $\mathrm{NaCl}$ (Figure S3). The Ru electrodes with $>0.003 \mathrm{M} \mathrm{Ru}$ addition all had strong OER efficiency (Figure 5c). The Mn-Mo-0.001 M Ru electrodes had poor physical stability leading to the large deviation between runs. The addition of Sn as a dopant led to a decrease in OER compared with the other dopants, with the Mn-Mo-0.003 M Sn electrode providing 88\% efficiency (Figure 5e). Out of the electrodes evaluated, the inclusion of Ru provided the best efficiency toward OER in $0.5 \mathrm{M} \mathrm{NaCl}$ (Figure 5) and also showed the highest charge passed toward OER in buffered $\mathrm{NaCl}$ (Figure $\mathrm{S} 3$ ). 


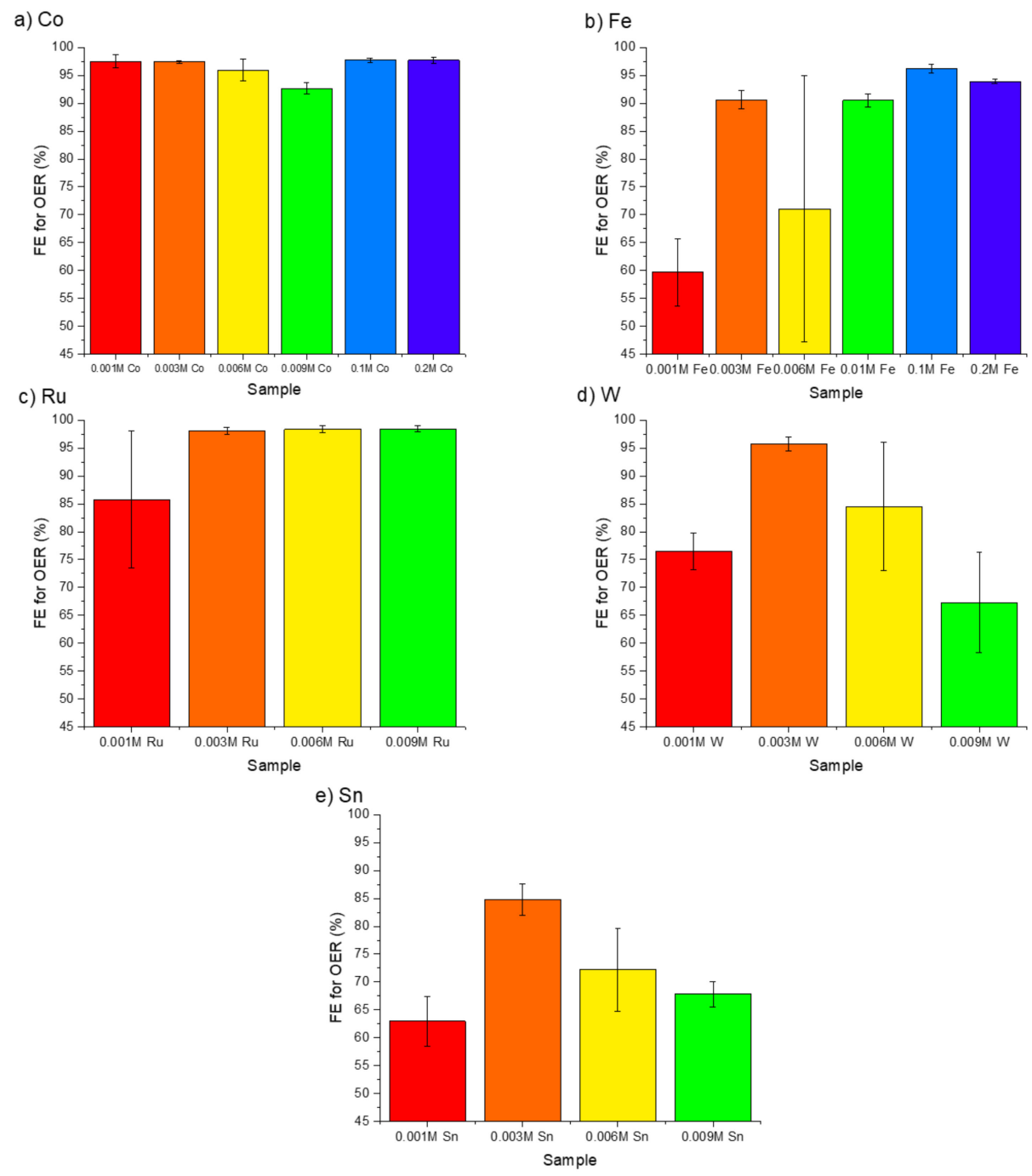

Figure 5. Comparison of the average OER faradaic efficiencies ( 3 subsequent measurements) following $30 \mathrm{~min}$ at $1.5 \mathrm{~V}$ (vs. $\mathrm{Ag} / \mathrm{AgCl}$ ) in $0.5 \mathrm{M} \mathrm{NaCl}$ for electrodes doped with (a) $\mathrm{Co},(\mathbf{b}) \mathrm{Fe}$, (c) $\mathrm{Ru}$, (d) W, and (e) Sn.

When testing in filtered raw seawater, most of the electrodes saw a slight decrease in OER faradaic efficiency compared with the neutral chloride solution. The differences may originate from the increased ionic concentration in seawater and the application from a higher kinetic overpotential ( $\mathrm{V}$ vs. RHE) given the increased buffering in seawater and, correspondingly, the higher $\mathrm{pH}$ in the anolyte compared to $0.5 \mathrm{M} \mathrm{NaCl}$. A summary of these tests is shown in Figure 6. The inclusion of Co (Figure 6a) generally maintained high OER faradaic efficiency, somewhat greater for the Mn-Mo-0.2 M Co electrode. Surprisingly, for Fe-containing electrodes (Figure 6b), the OER faradaic efficiency in seawater was notably greater than in $0.5 \mathrm{M} \mathrm{NaCl}$ for $0.001 \mathrm{M} \mathrm{Fe}$, generally decreasing with Fe content and reaching OER efficiencies notably lower than in $0.5 \mathrm{M} \mathrm{NaCl}$. This switch may be due to buffering occurring in seawater improving the Fe's stability in the electrode. Elucidation of this behavior change at low Fe doping levels will be a focus of future work. The Ru electrodes also performed well, >90\% efficiency for the electrodes at $0.003 \mathrm{M} \mathrm{Ru}$ and $0.009 \mathrm{M}$ $\mathrm{Ru}$ (Figure 6c). For W-containing electrodes, OER faradaic efficiencies were also somewhat higher in seawater, marginally greater for the Mn-Mo-0.003 M W (Figure 6d), which also had similar performance in artificial seawater (Figure S2). The Mn-Mo-0.003 M Sn electrode again had the best performance from the Sn set (Figure 6e). 
a) $\mathrm{Co}$

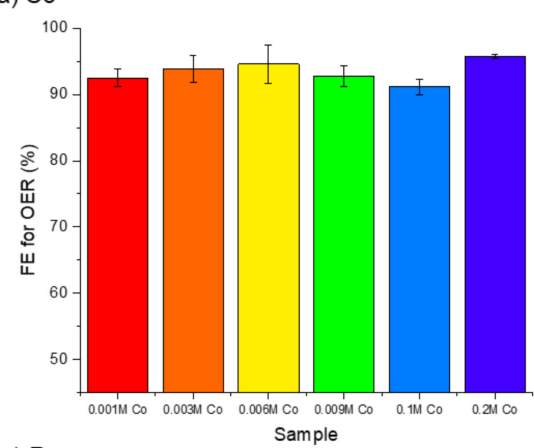

c) $\mathrm{Ru}$

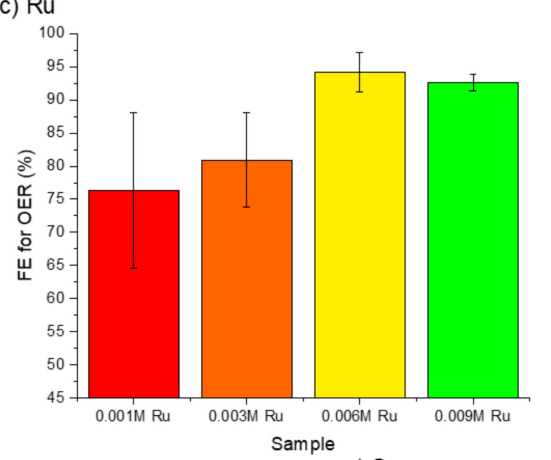

b) $\mathrm{Fe}$

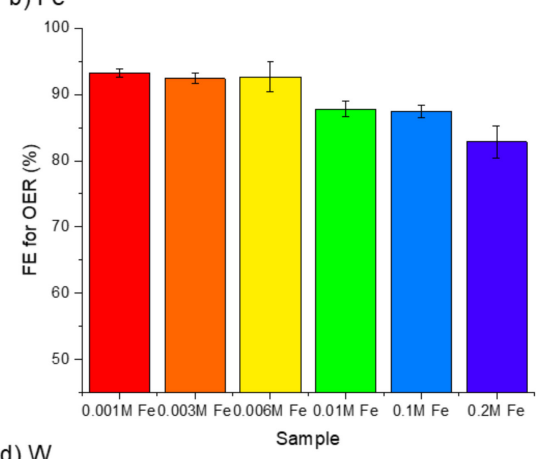

d) $\mathrm{W}$

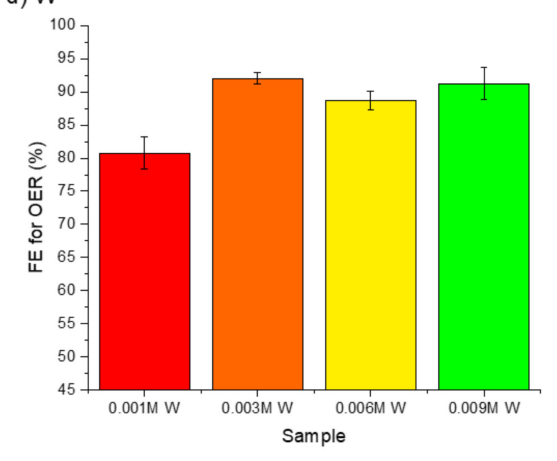

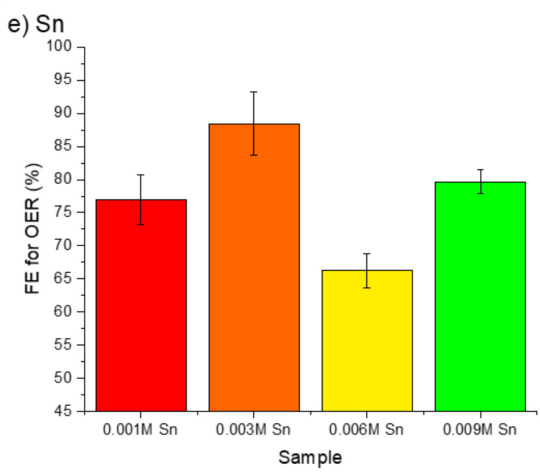

Figure 6. Comparison of the OER faradaic efficiency for replicate electrode samples following $30 \mathrm{~min}$ at $1.5 \mathrm{~V}$ (vs. $\mathrm{Ag} / \mathrm{AgCl}$ ) in raw filtered seawater for electrodes doped with (a) $\mathrm{Co},(\mathbf{b}) \mathrm{Fe},(\mathbf{c}) \mathrm{W},(\mathrm{d}) \mathrm{Ru}$, and (e) Sn.

While the OER faradaic efficiency is a crucial factor, the electrodes also need to sustain high catalytic activity at the anode to facilitate efficient HER at the cathode. A summary of the electrode performance both as OER faradaic efficiency and a measure of catalytic activity (total charge passed during the OER runs in seawater) can be seen in Figure 7. This comparison shows the promising performance of the Mn-Mo-Ru system, in addition to that measured in other electrolytes and at lower applied potentials in artificial seawater and phosphate buffer (Figure S4). The Mn-Mo-Sn electrodes had the second highest current; however, these electrodes were less efficient toward OER than the $\mathrm{Ru}$.

The Mn-Mo-Ru electrode system was the most promising for suppressing CER and maintaining high catalytic activity. However, the tests performed were relatively short term with a $30 \mathrm{~min}$ run length. To realize eventual maturation and deployment in a raw seawater electrolyzer, the stability of the electrodes needs to be assessed and likely improved. Figure $\mathrm{S} 5$ shows the measured current during the $30 \mathrm{~min}$ runs in raw seawater at $1.5 \mathrm{~V}$ (vs. $\mathrm{Ag} / \mathrm{AgCl}$ ) for the $\mathrm{Mn}-\mathrm{Mo}-0.006 \mathrm{M} \mathrm{Ru}$ and Mn-Mo-0.009 M Ru electrodes. While the Mn-Mo-0.006 M Ru electrode was initially more catalytically active, the activity decreased over time and, notably, in the second and third runs. In contrast, the initially lower activity of the Mn-Mo-0.009 M Ru was consistent throughout the runs, suggesting that doping level may have a trade-off between catalytical activity and stability. 


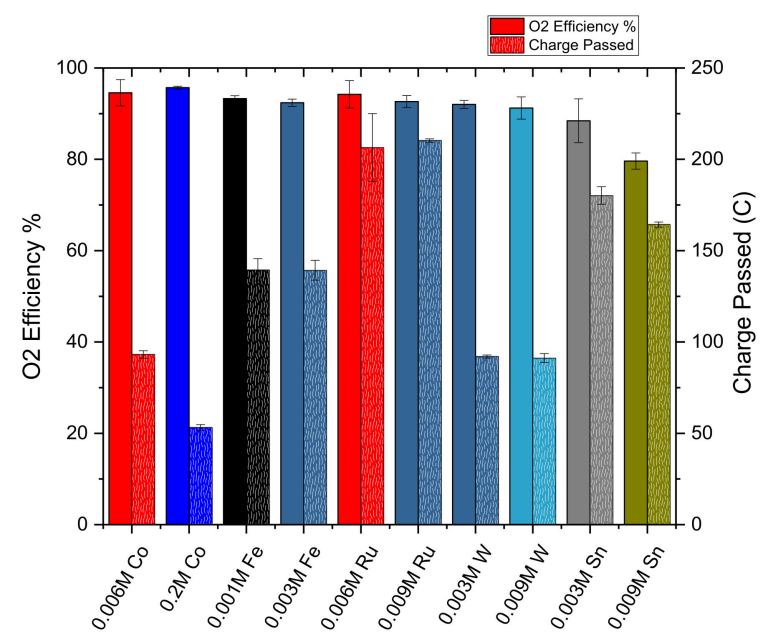

Figure 7. Comparison of the OER faradaic efficiency for replicate electrode samples following $30 \mathrm{~min}$ at $1.5 \mathrm{~V}$ (vs. $\mathrm{Ag} / \mathrm{AgCl}$ ) in raw filtered seawater for electrodes doped with $\mathrm{Co}, \mathrm{Fe}, \mathrm{W}, \mathrm{Ru}$, and $\mathrm{Sn}$.

Extending testing in a flowing seawater environment was also carried out at PNNL's Marine Sciences Lab. Seawater flowed through a flume at a rate of $75 \mathrm{~L} / \mathrm{min}$, with an average temperature of $22.0 \pm 1.1^{\circ} \mathrm{C}$, salinity of $31.9 \pm 0.4$ parts per thousand, and a bulk $\mathrm{pH}$ of $7.80 \pm 0.07$. The Mn-Mo-0.009 $\mathrm{M}$ Ru electrode was placed into the flume along with a Pt counter electrode and a $\mathrm{Ag} / \mathrm{AgCl}$ reference electrode. A $\mathrm{pH}$ probe was placed in close proximity $(\sim 5 \mathrm{~mm})$ to the anode and cathode to monitor local $\mathrm{pH}$. Pictures of the test system are shown in Figure 8. While gas or anolyte collection was not feasible in the flow setup to assess OER selectivity at this time, we expect comparable performance intermediate to the tested cases of raw seawater and buffered $\mathrm{NaCl}$ (due to the mitigation of $\mathrm{pH}$ swings by the flow rate).
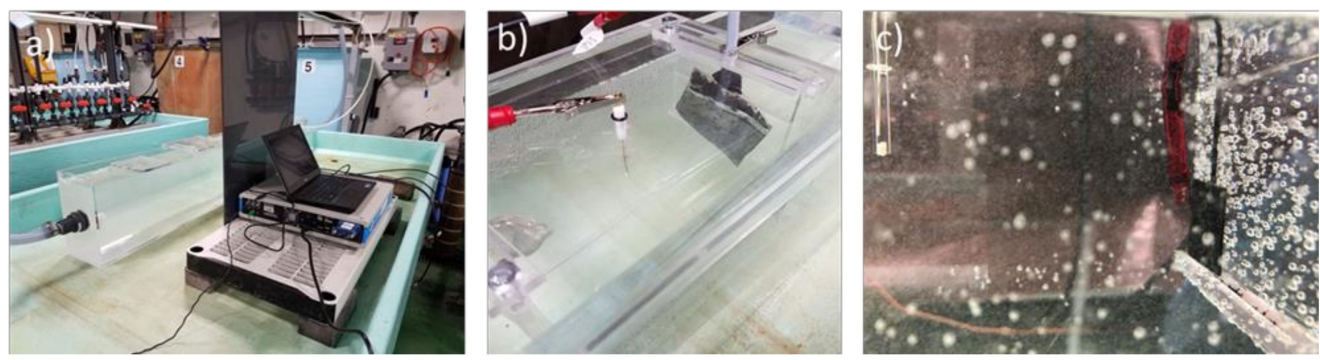

Figure 8. (a) The seawater flume electrochemical setup, (b) the electrochemical cell region in the flume, and (c) the test electrode within the flume showing the $\mathrm{pH}$ probe (red) near the surface.

A comparison was performed on Mn-Mo-Ru electrode stability based on the $\mathrm{pH}$ of the electrodeposition solution, through which achieving a more acidic solution is thought to generate a more durable catalyst. Figure 9 compares the chronoamperometric response for a Mn-Mo- $0.009 \mathrm{M} \mathrm{Ru}$ electrode prepared at either $\mathrm{pH} 1$ or $\mathrm{pH} 2$ in the seawater flume at $1.5 \mathrm{~V}$ (vs. $\mathrm{Ag} / \mathrm{AgCl}$ ). The $\mathrm{pH}$ 2-deposited electrode had higher catalytic activity than its $\mathrm{pH} 1$ counterpart. The rapid current increase at $\sim 1$ day for $\mathrm{pH} 1$ and $\sim 2$ days for $\mathrm{pH}$ 2 is believed to have occurred due to spalling from the electrode partially exposing the $\mathrm{IrO}_{2}$ underlayer, expected to decrease the OER faradaic efficiency due to the high CER activity of $\mathrm{IrO}_{2}$. Coating with a water-permeable polymer, such as Nafion, may improve the mechanical durability of anodes, maintaining or improving OER selectivity albeit at a slight compromise to activity (charge passed, Figure S5). 


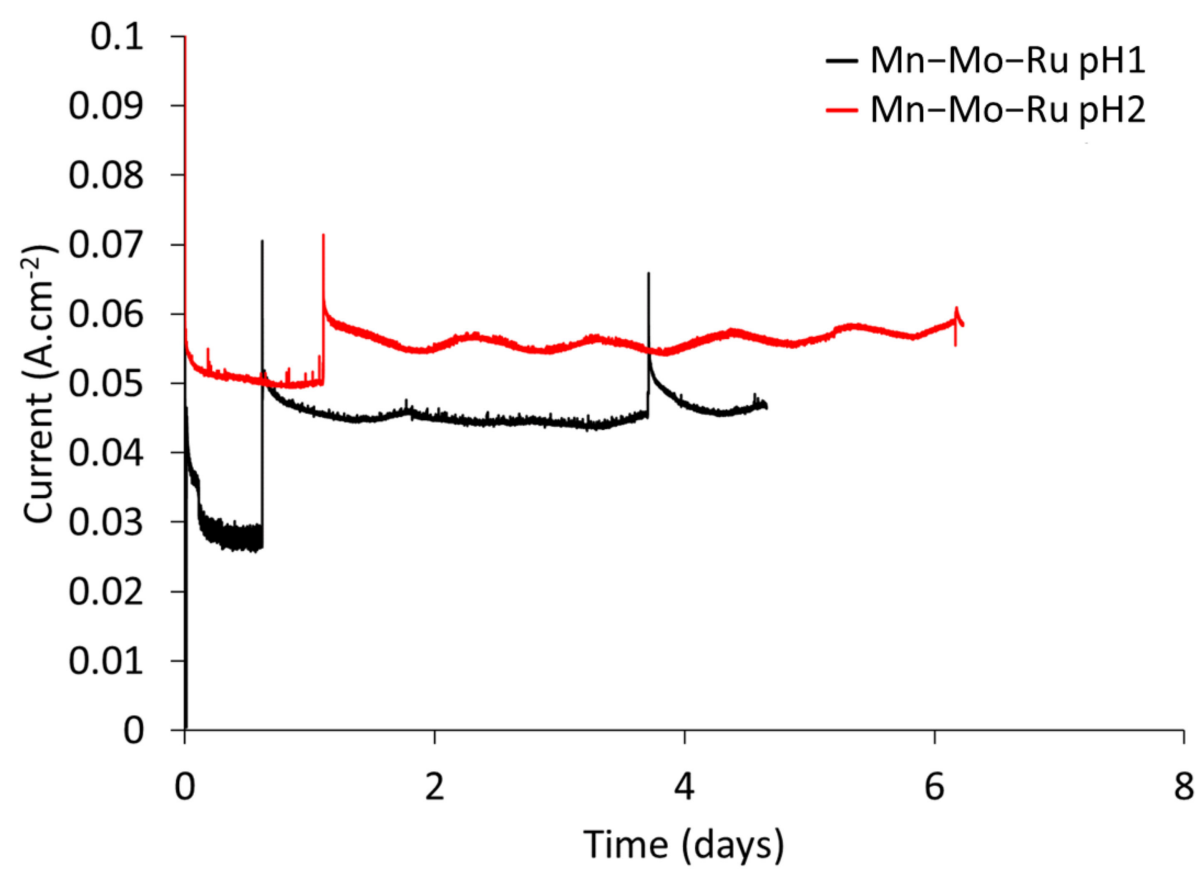

Figure 9. Chronoamperometric behavior of Mn-Mo-0.009 M Ru electrodes prepared at $\mathrm{pH} 1$ (black) and $\mathrm{pH} 2$ (red) in a flowing seawater flume at $1.5 \mathrm{~V}$ (vs. $\mathrm{Ag} / \mathrm{AgCl})$.

Chronopotentiometric measurements under an applied current of $10 \mathrm{~A} / \mathrm{cm}^{2}$ were also performed in the flowing seawater flume (Figure 10). The ohmic drop in this setup, assuming a seawater conductivity of $50 \mathrm{mS} / \mathrm{cm}$ and the average current in the text, was $26 \mathrm{mV}$. An undoped Mn-Mo electrode measured the highest overpotential averaging $1.52 \mathrm{~V} \pm 0.005 \mathrm{~V}$ (vs. $\mathrm{Ag} / \mathrm{AgCl}$ ) with average fluctuations of $10.7 \mathrm{mV}(7.06 \%)$. The Mn-Mo-0.006 M Ru electrode prepared at $\mathrm{pH} 1$ measured an improved overpotential at $1.49 \mathrm{~V} \pm 0.007 \mathrm{~V}$ (vs. $\mathrm{Ag} / \mathrm{AgCl})$ with average fluctuations of $5 \mathrm{mV}(0.31 \%)$ during the week-long electrolysis. The Mn-Mo-0.006 M Ru electrode prepared at $\mathrm{pH} 2$ suffered a surface failure almost immediately, and the resulting response measured matched that of an $\mathrm{IrO}_{2}$ electrode, with a low overpotential; however, it is known to be highly inefficient for OER over the CER. The Mn-Mo-0.006 M Ru pH 1 electrode did also show signs of spalling to expose the underlying $\mathrm{IrO}_{2}$ layer at the end of the 7-day exposure, as shown in Figure S7. Throughout the test, an accumulation of a salt deposit on the cathode was also observed, made primarily of $\mathrm{Mg}(\mathrm{OH})_{2}$ (Figure S7d). This deposit is expected to reduce functionality at longer test times but can be cleaned with anodic polarization. In application, this deposit could be harvested for its content of critical minerals or value-added elements in a co-generation process. Moreover, of note in a closer analysis of the Mn-Mo-0.006 M Ru catalyst postchronoamperometric measurement was an apparent enrichment of Ru appearing following the test, as shown in the EDS maps of Figure 11. Here, the exposed $\mathrm{IrO}_{2}$ can be seen, but in the central region of the image, Ru appeared to be enriched near the edges of the catalyst sections. Only a single area on the sample was imaged. 


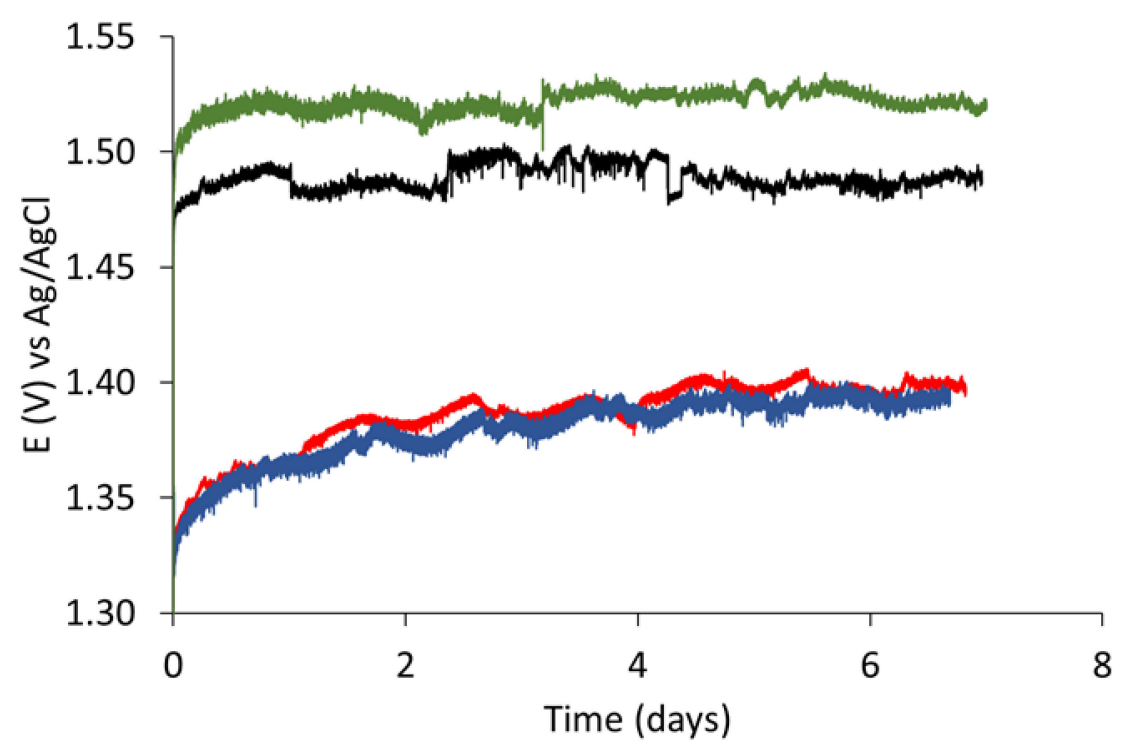

-Mn-Mo-Ru pH 1 -Mn-Mo-Ru pH 2 -IrO2 - Mn-Mo pH 1

Figure 10. Chronopotentiometric behavior of Mn-Mo-based electrodes compared with $\mathrm{IrO}_{2}$ in a flowing seawater flume at $10 \mathrm{~A} / \mathrm{cm}^{2}$ applied current.
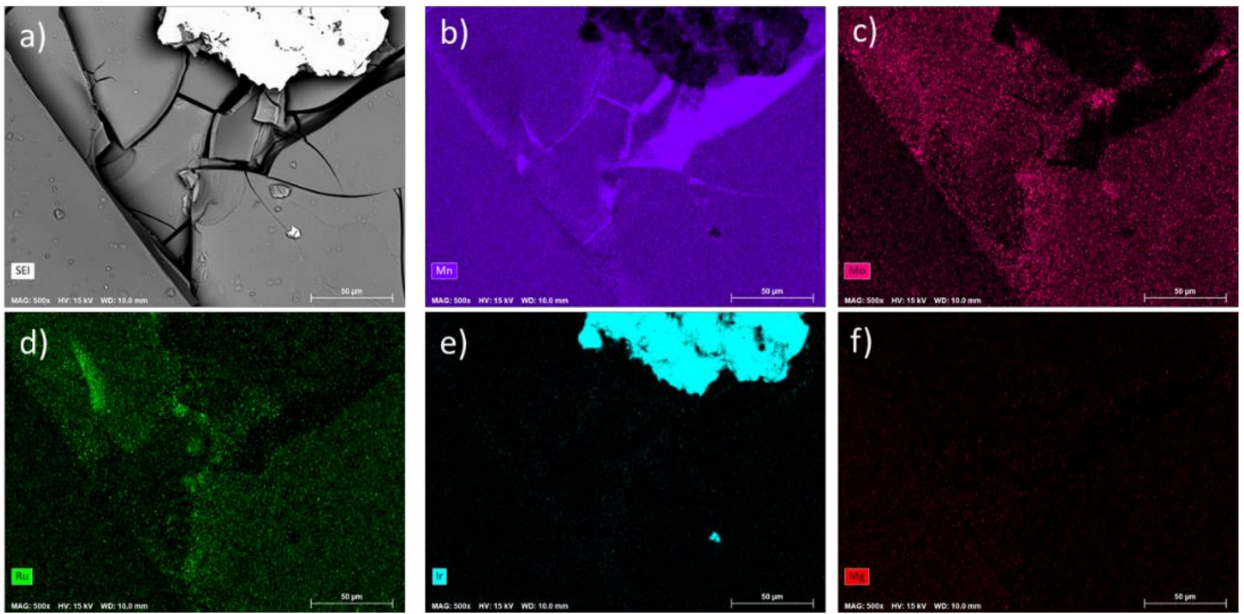

Figure 11. (a) SEM micrograph of the Mn-Mo-0.006 M Ru catalyst following chronoamperometric study in a raw seawater flume and the corresponding EDS maps for (b) Mn, (c) Mo, (d) Ru, (e) Ir, and (f) $\mathrm{Mg}$.

\section{Discussion}

The results of this study show the effectiveness of doping transition metals into Mn-Mo-X catalysts to suppress the CER and improve overall catalytic activity. The bestperforming dopant was Ru in terms of efficiency for OER over CER and catalytic activity. However, despite previous reports of this doping approach being successful for CER suppression, little mechanistic discussion is present in the literature. With the similar response of multiple dopants (Fe, $\mathrm{Sn}, \mathrm{W}$, and $\mathrm{Co}$ ) and the enhanced activity of a known catalytically active species, $\mathrm{Ru}$, dopants may play a role in manipulating the coating density and stability in addition to serving as active catalytic sites. Evidence on both mechanistic roles exists. Ru and Ir are industrial benchmark catalysts for efficient oxygen and chlorine evolution (in the chlor-alkali process), sitting high on the volcano curve for both OER [33] and CER [34]. In the case of IrOx, the OER is not suppressed or influenced by the CER occurring on the same surface, showing scaling between the two reactions on active catalysts [35]. Targeting selective OER over CER can present a challenge but may 
be realized through a combination of processes. The base catalyst in this study, Mn, is well documented to have a lower overpotential for oxygen evolution than for chlorine evolution [36], while the Mo serves to stabilize the $\mathrm{Mn}$ and partially enhance catalytic activity [6]. The work on alkali and alkali-earth intercalated $\mathrm{MnO}_{2}$ has shown that inducing structural disorder and the presence of oxygen vacancies can create a preference for the OER over CER [37]. The presence of transition metal oxides in the electrodeposited $\mathrm{MnO}_{2}$ will induce disorder and potentially create bridging mismatches leading to oxygen vacancies. The role of defects within transition and noble metal catalysts to enhance catalytic water splitting ability has also been highlighted recently, especially on Co electrocatalysts [7].

The adsorbed intermediates generated for the CER can also influence selectivity. Surfaces that form a $\mathrm{M}-\mathrm{Cl}$ intermediate can efficiently sustain the $\mathrm{CER}$, while the generation of the $\mathrm{M}-\mathrm{OCl}$ intermediate will suppress the CER [38]. The $\mathrm{OCl}$ intermediate route further suppresses the $\mathrm{CER}$ on $\mathrm{RuO}_{2}$ with increasing $\mathrm{pH}$ due to the change in Gibbs free energy loss. Studies of preferential OER in halide-containing environments on NiB and CoP catalysts suggest that the edge sites on the metalate clusters are crucial to sustaining the OER, as $\mathrm{H}_{2} \mathrm{O}$ will out compete halides for these sites, increasing the likelihood of OER over CER. With the small locations and disordered distribution of the Ru dopants in this study, a higher number of edge sites may dictate an added preference to OER over CER via oxygen-containing intermediates [39]. Ab initio assessment of reaction intermediate binding energies on doped Mn-Mo oxide surfaces and high-index facets would help assess whether Ru plays such roles in the present system. While the partial dissolution and oxidation of $\mathrm{RuO}_{2}$ cannot currently be ruled out as a contribution to the measured activity, the presence of $\mathrm{Ru}$ on the catalyst after extended seawater testing suggests this contribution would be minimal. Many other candidate dopants (and combinations thereof) are available to be tested in a similar approach, and this work shows that dopants that are catalytically active toward CER can also be considered for preferential OER on Mn-Mo-X catalysts.

This work was performed with a long-term view of realizing direct seawater electrolysis as a means of energy storage and direct fuel production from marine hydrokinetic power (MHK) and other off-shore power sources. To mature the use of Mn-Mo-X catalysts for this application, challenges remain in the durability of the catalyst stack. A primary target should be the sustained life of the catalysts in operation. During the electrodeposition process, competitive water oxidation can create gaps between the base material (here, the Ti plate), the conductive $\mathrm{IrO}_{2}$ layer, and the catalyst itself. The use of a Nafion coating can improve the durability of the catalyst, but improved fabrication approaches where dense catalyst layers can be formed are a necessity, apparent from the long-term testing in raw seawater.

Although the neutral $\mathrm{pH}$ considered here comes at some sacrifice in catalytic performance toward OER/HER, it could provide additional benefits to realizing direct seawater electrolysis. Such a pH can improve catalyst and dopant stability and further increase selectivity toward OER compared to acidic media [38]. A flowing seawater feed in a membrane-less design could yield these conditions and save costs associated with the membrane and cooling requirements in a deployed electrolyzer [40,41]. The cathode fouling by the $\mathrm{Mg}(\mathrm{OH})_{2}$-rich deposits observed in bulk seawater testing in this work may limit HER. In situ treatment of this deposit requires investigation to ensure any applied method does not negatively influence the CER-suppressing anode [42].

\section{Conclusions}

In conclusion, this work showed the improved catalytic efficiency and OER selectivity of Mn-Mo-Ru catalysts over previously studied transition metal-doped Mn-Mo catalysts. In both $\mathrm{NaCl}$ solution and raw seawater, the $\mathrm{Mn}-\mathrm{Mo}-\mathrm{Ru}$ catalysts demonstrated strong performance toward OER with reduced CER. Extended testing in continuous raw seawater highlighted the need for further improvement of the Mn-Mo catalysts. This work highlighted that common catalysts, such as Ru, can be used as successful dopants in CER-suppressing catalysts. 
Supplementary Materials: The following are available online at https://www.mdpi.com/article/10 .3390 /app112411911/s1, Figure S1: SEM micrographs at 500× of (a) 0.2 M Mn-0.003 M Mo-0.003 M W, (b) 0.2 M Mn-0.003 M Mo-0.009 M Ru, and (c) 0.2 M Mn-0.003 M Mo-0.1 M Co. Figure S2: (a) XPS survey spectra from the Mn-Mo-0.006 M Ru electrode and associated spectra from the Ru 3p region for the (b) Mn-Mo-0.006 M Ru and (c) Mn-Mo electrodes and the Ru 3d region of the (d) Mn-Mo-0.009 M Ru and (e) Mn-Mo electrodes. Figure S3: (a) FE toward OER after $30 \mathrm{~min}$ in artificial seawater (ASW) and $0.1 \mathrm{M}$ phosphate buffer + 0.5 M NaCl (PB) for different transition metal-doped Mn-Mo catalyst. (b) Charge passed toward OER in noted electrolyte, calculated by taking the FE * the total charge passed after $30 \mathrm{~min}$. Figure S4: Charge passed toward OER in ASW and PB for different concentrations of $\mathrm{Co}-$ and Ru-doped Mn-Mo catalysts. Figure S5: Chronoamperometric analysis for (a) Mn-Mo-0.006 M Ru and (b) Mn-Mo-0.009 M Ru in raw seawater indicates that 0.009 M Rucontaining electrode has better stability. Figure S6: (a) FE toward OER and (b) charge passed toward OER at 60, 90, and $120 \mathrm{~min}$ in artificial seawater (ASW) for bare (Blue) and Nafion ${ }^{\circledR}{ }^{-}$-coated Mn-Mo$0.006 \mathrm{M}$ Ru electrode. Figure S7: Comparison of Mn-Mo-0.006 M Ru electrode ( $\mathrm{pH}$ 1) following chronopotentiometric testing in raw seawater flume both (a) before and (b) after testing showing (c) exposure of the $\mathrm{IrO}_{2}$ base layer in the EDS map, and (d) the cathode following seawater testing showing deposition of a salt layer.

Author Contributions: Conceptualization R.M.A., K.A.S., and G.A.G.; methodology, P.A., N.D., R.M.A., K.A.S., and L.-J.K.; formal analysis, P.A., N.D., R.M.A., and K.A.S.; investigation, P.A., N.D., N.M.A., J.A.S., L.-J.K., C.W., D.M.S., M.H.E., and J.V.C.; resources, N.D. and D.M.S.; data curation, P.A., N.D., M.H.E., and J.V.C.; writing-original draft preparation, P.A., N.D., R.M.A., and K.A.S.; writing-review and editing, P.A., R.M.A., and K.A.S. All authors have read and agreed to the published version of the manuscript.

Funding: The research described in this paper/on this poster/in this report was conducted under the Laboratory Directed Research and Development Program at Pacific Northwest National Laboratory, a multiprogram national laboratory operated by Battelle for the U.S. Department of Energy and the Department of Energy Office of Energy Efficiency and Renewable Energy (DOE EERE) Water Power Technology's Seedling Program.

Data Availability Statement: The data presented in this study are available on request from the corresponding author. The data are not publicly available due to ongoing proprietary research.

Acknowledgments: K.A.S. acknowledges support from Oregon State University as a Callahan Faculty Scholar. P.A. acknowledges support from the Link Foundation Energy Fellowship. R.M.A acknowledges the staff at the PNNL Marine Sciences Laboratory and Charles Brandt and Genevra HarkerKlimes for programmatic support. XPS measurements were performed using EMSL (grid.436923.9), a DOE Office of Science User Facility sponsored by the Office of Biological and Environmental Research. R.M.A and N.D. acknowledge the support of the Laboratory Directed Research and Development Program at Pacific Northwest National Laboratory.

Conflicts of Interest: The authors declare no conflict of interest.

\section{References}

1. Tong, W.; Forster, M.; Dionigi, F.; Dresp, S.; Sadeghi Erami, R.; Strasser, P.; Cowan, A.J.; Farràs, P. Electrolysis of low-grade and saline surface water. Nat. Energy 2020, 5, 367-377. [CrossRef]

2. Webber, M.E. The water intensity of the transitional hydrogen economy. Environ. Res. Lett. 2007, 2, 034007. [CrossRef]

3. Dresp, S.R.; Dionigi, F.; Klingenhof, M.; Strasser, P. Direct electrolytic splitting of seawater: Opportunities and challenges. ACS Energy Lett. 2019, 4, 933-942. [CrossRef]

4. Hansen, H.A.; Man, I.A.; Studt, F.; Abild-Pedersen, F.; Bligaard, T.; Rossmeisl, J. Electrochemical chlorine evolution at rutile oxide (110) surfaces. Phys. Chem. Chem. Phys. 2010, 12, 283-290. [CrossRef]

5. El-Moneim, A.A.; Bhattarai, J.; Kato, Z.; Izumiya, K.; Kumagai, N.; Hashimoto, K. Mn-Mo-Sn oxide anodes for oxygen evolution in seawater electrolysis for hydrogen production. ECS Trans. 2010, 25, 127. [CrossRef]

6. El-Moneim, A.A.; Kumagai, N.; Asami, K.; Hashimoto, K. Nanocrystalline manganese-molybdenum-tungsten oxide anodes for oxygen evolution in acidic seawater electrolysis. Mater. Trans. 2005, 46, 309-316. [CrossRef]

7. Vos, J.; Koper, M. Measurement of competition between oxygen evolution and chlorine evolution using rotating ring-disk electrode voltammetry. J. Electroanal. Chem. 2018, 819, 260-268. [CrossRef]

8. Vos, J.G.; Wezendonk, T.A.; Jeremiasse, A.W.; Koper, M.T. MnOx/IrOx as selective oxygen evolution electrocatalyst in acidic chloride solution. J. Am. Chem. Soc. 2018, 140, 10270-10281. [CrossRef] [PubMed] 
9. Amikam, G.; Nativ, P.; Gendel, Y. Chlorine-free alkaline seawater electrolysis for hydrogen production. Int. J. Hydrogen Energy 2018, 43, 6504-6514. [CrossRef]

10. Kuang, Y.; Kenney, M.J.; Meng, Y.; Hung, W.-H.; Liu, Y.; Huang, J.E.; Prasanna, R.; Li, P.; Li, Y.; Wang, L. Solar-driven, highly sustained splitting of seawater into hydrogen and oxygen fuels. Proc. Natl. Acad. Sci. USA 2019, 116, 6624-6629. [CrossRef]

11. Juodkazytè, J.; Šebeka, B.; Savickaja, I.; Petrulevičienè, M.; Butkutè, S.; Jasulaitienè, V.; Selskis, A.; Ramanauskas, R. Electrolytic splitting of saline water: Durable nickel oxide anode for selective oxygen evolution. Int. J. Hydrogen Energy 2019, 44, 5929-5939. [CrossRef]

12. Dresp, S.R.; Dionigi, F.; Klingenhof, M.; Merzdorf, T.; Schmies, H.; Drnec, J.; Poulain, A.; Strasser, P. Molecular Understanding of the Impact of Saline Contaminants and Alkaline $\mathrm{pH}$ on NiFe Layered Double Hydroxide Oxygen Evolution Catalysts. ACS Catal. 2021, 11, 6800-6809. [CrossRef]

13. Karlsson, R.K.; Cornell, A. Selectivity between oxygen and chlorine evolution in the chlor-alkali and chlorate processes. Chem. Rev. 2016, 116, 2982-3028. [CrossRef]

14. Exner, K.S.; Over, H. Beyond the rate-determining step in the oxygen evolution reaction over a single-crystalline IrO2 (110) model electrode: Kinetic scaling relations. ACS Catal. 2019, 9, 6755-6765. [CrossRef]

15. Exner, K.S. Controlling stability and selectivity in the competing chlorine and oxygen evolution reaction over transition metal oxide electrodes. ChemElectroChem 2019, 6, 3401-3409. [CrossRef]

16. Zheng, J. Seawater splitting for high-efficiency hydrogen evolution by alloyed PtNix electrocatalysts. Appl. Surf. Sci. 2017, 413, 360-365. [CrossRef]

17. Zheng, J. Pt-free NiCo electrocatalysts for oxygen evolution by seawater splitting. Electrochim. Acta 2017, 247, 381-391. [CrossRef]

18. Cheng, F.; Feng, X.; Chen, X.; Lin, W.; Rong, J.; Yang, W. Synergistic action of Co-Fe layered double hydroxide electrocatalyst and multiple ions of sea salt for efficient seawater oxidation at near-neutral pH. Electrochim. Acta 2017, 251, 336-343. [CrossRef]

19. Hsu, G.-S.W.; Lu, Y.-F.; Hsu, S.-Y. Effects of electrolysis time and electric potential on chlorine generation of electrolyzed deep ocean water. J. Food Drug Anal. 2017, 25, 759-765. [CrossRef] [PubMed]

20. Fujimura, K.; Izumiya, K.; Kawashima, A.; Akiyama, E.; Habazaki, H.; Kumagai, N.; Hashimoto, K. Anodically deposited manganese-molybdenum oxide anodes with high selectivity for evolving oxygen in electrolysis of seawater. J. Appl. Electrochem. 1999, 29, 769-775. [CrossRef]

21. Fujimura, K.; Matsui, T.; Izumiya, K.; Kumagai, N.; Akiyama, E.; Habazaki, H.; Kawashima, A.; Asami, K.; Hashimoto, K. Oxygen evolution on manganese-molybdenum oxide anodes in seawater electrolysis. Mater. Sci. Eng. A 1999, 267, 254-259. [CrossRef]

22. El-Moneim, A. Mn-Mo-W-oxide anodes for oxygen evolution during seawater electrolysis for hydrogen production: Effect of repeated anodic deposition. Int. J. Hydrogen Energy 2011, 36, 13398-13406. [CrossRef]

23. Dionigi, F.; Reier, T.; Pawolek, Z.; Gliech, M.; Strasser, P. Design criteria, operating conditions, and nickel-iron hydroxide catalyst materials for selective seawater electrolysis. ChemSusChem 2016, 9, 962-972. [CrossRef]

24. Vesborg, P.C.; Jaramillo, T.F. Addressing the terawatt challenge: Scalability in the supply of chemical elements for renewable energy. Rsc Adv. 2012, 2, 7933-7947. [CrossRef]

25. Kato, Z.; Sato, M.; Sasaki, Y.; Izumiya, K.; Kumagai, N.; Hashimoto, K. Electrochemical characterization of degradation of oxygen evolution anode for seawater electrolysis. Electrochim. Acta 2014, 116, 152-157. [CrossRef]

26. Fujimura, K.; Matsui, T.; Habazaki, H.; Kawashima, A.; Kumagai, N.; Hashimoto, K. The durability of manganese-molybdenum oxide anodes for oxygen evolution in seawater electrolysis. Electrochim. Acta 2000, 45, 2297-2303. [CrossRef]

27. Tian, L.; Li, Z.; Xu, X.; Zhang, C. Advances in noble metal ( $\mathrm{Ru}, \mathrm{Rh}$, and Ir) doping for boosting water splitting electrocatalysis. J. Mater. Chem. A 2021, 9, 13459-13470. [CrossRef]

28. Gwag, E.H.; Moon, S.Y.; Mondal, I.; Park, J.Y. Influence of carbon doping concentration on photoelectrochemical activity of TiO 2 nanotube arrays under water oxidation. Catal. Sci. Technol. 2019, 9, 688-694. [CrossRef]

29. Moon, S.Y.; Gwag, E.H.; Park, J.Y. Hydrogen Generation on Metal/Mesoporous Oxides: The Effects of Hierarchical Structure, Doping, and Co-catalysts. Energy Technol. 2018, 6, 459-469. [CrossRef]

30. Holt-Hindle, P.; Nigro, S.; Asmussen, M.; Chen, A. Amperometric glucose sensor based on platinum-iridium nanomaterials. Electrochem. Commun. 2008, 10, 1438-1441. [CrossRef]

31. Subow, N. Oceanographical Tables; USSR. Oceanogr. Inst. Hydro-Meteorol. Com Mosc.: Moscow, Russia, 1931 ; Volume 208.

32. Kim, K.; Winograd, N. X-ray photoelectron spectroscopic studies of ruthenium-oxygen surfaces. J. Catal. 1974, 35, 66-72. [CrossRef]

33. Yu, J.; He, Q.; Yang, G.; Zhou, W.; Shao, Z.; Ni, M. Recent Advances and Prospective in Ruthenium-Based Materials for Electrochemical Water Splitting. ACS Catal. 2019, 9, 9973-10011. [CrossRef]

34. Exner, K.S. Beyond thermodynamic-based material-screening concepts: Kinetic scaling relations exemplified by the chlorine evolution reaction over transition-metal oxides. Electrochim. Acta 2020, 334, 135555. [CrossRef]

35. Trasatti, S. Electrocatalysis in the anodic evolution of oxygen and chlorine. Electrochim. Acta 1984, 29, 1503-1512. [CrossRef]

36. Izumiya, K.; Akiyama, E.; Habazaki, H.; Kawashima, A.; Asami, K.; Hashimoto, K.; Kumagai, N. Surface activation of manganese oxide electrode for oxygen evolution from seawater. J. Appl. Electrochem. 1997, 27, 1362-1368. [CrossRef]

37. Abe, H.; Murakami, A.; Tsunekawa, S.; Okada, T.; Wakabayashi, T.; Yoshida, M.; Nakayama, M. Selective Catalyst for Oxygen Evolution in Neutral Brine Electrolysis: An Oxygen-Deficient Manganese Oxide Film. ACS Catal. 2021, 11, 6390-6397. [CrossRef] 
38. Exner, K.S. Design criteria for the competing chlorine and oxygen evolution reactions: Avoid the $\mathrm{OCl}$ adsorbate to enhance chlorine selectivity. Phys. Chem. Chem. Phys. 2020, 22, 22451-22458. [CrossRef]

39. Keane, T.P.; Nocera, D.G. Selective Production of Oxygen from Seawater by Oxidic Metallate Catalysts. ACS Omega 2019, 4, 12860-12864. [CrossRef]

40. Pang, X.; Davis, J.T.; Harvey, A.D.; Esposito, D.V. Framework for evaluating the performance limits of membraneless electrolyzers. Energy Environ. Sci. 2020, 13, 3663-3678. [CrossRef]

41. Hadikhani, P.; Hashemi, S.M.H.; Schenk, S.A.; Psaltis, D. A membrane-less electrolyzer with porous walls for high throughput and pure hydrogen production. Sustain. Energy Fuels 2021, 5, 2419-2432. [CrossRef]

42. Abbaspour, A.; Esmaeilbeig, A.R.; Jarrahpour, A.A.; Khajeh, B.; Kia, R. Aluminium(III)-selective electrode based on a newly synthesized tetradentate Schiff base. Talanta 2002, 58, 397-403. [CrossRef] 